\title{
Implementasi Digital Marketing Terhadap Peningkatan Penjualan Hasil Home Industri
}

\author{
Risa Ratna Gumilang \\ STIE Sebelas April Sumedang \\ Risa.rgumilang@gmail.com
}

\begin{abstract}
ABSTRAK
Perkembangan teknologi informasi yang berkembang sangat pesat berpengaruh bagi masyarakat dalam mendukung berbagai kegiatan bisnis baik besar maupun kecil agar dapat dikenal secara global. Dampak yang paling nyata adalah selain dikenal juga dapat meningkatkan volume penjualan dan profit. Digital Marketing adalah salah satu media pemasaran yang sangat besar memberikan pengaruh. Dengan menggunakan digital marketing dalam hal ini adalah media sosial, Para pengrajin patung pahatan asal Cipacing Bandung memasarkan hasil indutri rumahan berupa kerajinan tangan dari sebongkah kayu yang tidak terpakai dipahat menjadi patung-patung yang unik. Awalnya kegiatan ini hanya sebagai pengisi waktu luang, tetapi saat ini justru menjadi kegiatan utama sebagai penambah perputaran ekonomi dalam rumah tangga. Dahulu kegiatan penjualan hasil industri ini secara konvesional maupun tradisional, mereka membuat produk hanya berdasarkan pesanan. Tetapi setelah mengenal adanya media sosial sebagian warga cipacing ini sudah mulai menerima banyak pesanan, sehingga volume penjualan semakin meningkat pesat dibandingkan saaat penjualan dengan cara lama. Digital marketing dipandang sebagai media yang paling baik sebagai sarana promosi yang paling efektif dan efisien serta mampu meningkatkan volume penjualan yang signifikan,
\end{abstract}

Kata Kunci: Peningkatan Penjualan, Home Industri

\section{ABSTRACT}

Development of information technology is developing very faster now influencing the community in supporting various business activities both large and small to be known globally. The most obvious impact is not only being known but also increasing the volume of sales and profits. Digital Marketing is one of the very large marketing media that has an influence. By using digital marketing in this case is social media, sculpture carvings from Cipacing Bandung market the results of home industry in the form of handicrafts from a piece of unused wood carved into a unique sculpture. Initially this activity was only as a free time, but at this time it became the main activity as an increase in economic turnover in the household. Formerly the sales activities of these industrial products were conventional and traditional, they make products only on order. But after getting to know about the existence of some social cipacing residents, they have started to receive a lot of orders, so the sales volume is increasing faster compared to when selling with the old way. Digital marketing is seen as the best media as the most effective and efficient promotional tool and able to increase sales volume significantly.

Keyword : increase in Sales, Home Industri

\section{PENDAHULUAN}

Perkembangan teknologi informasi sangat berkembang pesat, berbagai kegiatan bisnis kecil sampai besar memanfaatkan perkembangan ini untuk menjalankan usahanya. Banyaknya competitor menjadi pertimbangan bagi para pengusaha untuk masuk dalam persaingan yang sangat ketat. Strategi pemasaran dan media yang tepat digunakan untuk bisa meraih pasar yang dituju sehingga volume penjualan selalu meningkat dan profit. Digital Marketing adalah salah satu media pemasaran yang saat ini sedang banyak diminati oleh masyarakat untuk medukung berbagai kegiatan yang dilakukan. Mereka sedikit demi sedikit mulai meninggalkan model pemasaran konvesional/tradisional beralih ke pemasaran modern yaitu digital marketing. Dengan digital marketing komunikasi dan transaksi dapat dilakukan setiap waktu/real time dan bisa mengglobal atau mendunia. Dengan jumlah pengguna social media berbasis chat ini yang banyak dan semakin hari semakin bertambah membuka peluang bagi UKM untuk mengembangkan pasarnya dalam genggaman smartphone. Survei yang dilakukan sepanjang 2016 itu menemukan bahwa 132,7 juta orang Indonesia telah terhubung ke internet. Adapun 
total penduduk Indonesia sendiri sebanyak 256,2 juta orang. Hal ini mengindikasikan kenaikan 51,8 persen dibandingkan jumlah pengguna internet pada 2014 lalu.

Survei yang dilakukan APJII pada 2014 hanya ada 88 juta pengguna internet. "Penyebabnya adalah perkembangan infrastruktur dan mudahnya mendapatkan smartphone atau perangkat genggam," terang Ketua APJII Jamalul Izza saat ditemui Kompas Tekno di sela pengumuman Riset Pengguna Internet Indonesia 2016, di Jakarta, Senin (24/10/2016), Kompas. Seperti halnya yang saat ini sedang dilakukan oleh sebagian warga cipacing dalam memasarkan hasil industri rumahannya yaitu kerajinan tangan. Industri rumahan saat ini menjadi kegiatan yang memiliki peran besar dalam membantu perputaran ekonomi rumah tangga.

Dalam mendukung kegiatan tersebut, banyak warga yang sudah menggunakan telepon genggam atau smartphone yang cukup modern. Rupanya mereka juga sudah mengenal dan melakukan kegiatan pemasaran dengan memanfaatkan smartphone tersebut. Komunikasi yang dilakukan adalah dengan telepon langsung, sms, dan sudah mulai menggunakan media sosial untuk melakukan penawaran seperti BBM (blackbbery Mesangger), FB (Facebook), WA (Whatsapp), IG (Instagram). Berdasarkan alasan di atas penulis tertarik untuk melakukan penelitian apakah media sosial bagian dari digital marketing yang digunakan, memberikan pengaruh terhadap volume penjualan industri rumahan mereka.

\section{Rumusan Masalah}

Mengacu dari latar belakang di atas maka secara umum rumusan masalah adalah bagaimana mengimplementasikan digital marketing, apakah berpengaruh dalam meningkatkan volume penjualan hasil industri rumahan.

Banyak hal yang mempengaruhi peningkatan volume penjualan, promosi, periklanan, kualitas produk, harga dan lain-lain. Disamping itu dalam digital marketing juga ada social media dan search engine optimation.

\section{Tujuan}

Berdasarkan rumusan masalah di atas maka tujuan penelitian ini secara umum mendeskripsikan bagaimana mengimplementasikan digital marketing apakah dapat memberikan pengaruh terhadap peningkatan volume penjualan hasil industri rumahan warga Cipacing Bandung.

Secara umum manfaat dari penelitian adalah untuk mengetahui apakah digital marketing dapat memberikan pengaruh terhadap peningkatan volume penjualan dari hasil industri rumahan tersebut. Bagi penulis adalah sebagai suatu ekperimen untuk menambah wawasan yang dapat dipakai acuan untuk melakukan penelitian selanjutnya. Untuk sebagian warga Cipacing bisa sebagai wacana baru agar semakin berinovasi dalam memasarkan hasil industri rumahannya.

\section{TINJAUAN PUSTAKA}

Turban et al. (2013), Katawetawaraks dan Wang (2014) menjelaskan bahwa belanja online adalah kegiatan pembelian produk (baik barang ataupun jasa) melalui media internet. Kegiatan belanja online meliputi kegiatan Business to Business (B2B) maupun Business to Consumers (B2C). Sementara pada penelitian kegiatan belanja online dikaitkan dengan $\mathrm{B} 2 \mathrm{C}$ karena kegiatan pembelian yang dimaksudkan adalah kegiatan pembelian yang digunakan oleh konsumen sendiri, tidak dijual kembali. Kegiatan belanja online di sini adalah transaksi yang bersifat ritel dengan pembeli individu, sehingga belanja online di sini adalah sebuah keputusan pembelian yang dilakukan oleh individu secara online.

E-marketing di dalamnya (Chaffey, 2015). Sebenarnya e-marketing merupakan pengembangan dari marketing tradisional dimana marketing tradisional adalah suatu proses pemasaran melalui media komunikasi offline seperti melalui penyebaran brosur, iklan di televisi dan radio, dan lain sebagainya. Setelah maraknya internet dan kemudahan komunikasi yang ditawarkanya, maka penerapan marketing pada perusahaan mulai mengadopsi media internet, yang kemudian disebut sebagai e-marketing.

Sedangkan menurut Kotler dalam Widodo (2014) internet marketing memiliki lima keuntungan besar bagi perusahaan yang menggunakannya. Pertama, baik perusahaan kecil maupun perusahaan besar dapat melakukannya. Kedua, tidak terdapat batas nyata dalam ruang beriklan jika dibandingkan dengan media cetak dan media penyiaran. Ketiga, akses dan pencarian keterangan sangat cepat jika dibandingkan dengan surat kilat atau bahkan fax. Keempat, situsnya dapat dikunjungi oleh siapapun, dimanapun di dalam dunia ini, kapanpun. Kelima, belanja dapat dilakukan secara lebih cepat dan sendirian.

(Sarwono dan Prihartono:2012) mengemukakan bahwa teknik yang memudahkan akses dan publikasi informasi menggunakan interaksi sosial melalui sosial media. Kemudian Aloysius Bagas Pradipta Irianto dalam jurnalnya berjudul pemanfaatan sosial media untuk meningkatkan market share UKM, Pada saat ini terdapat dua jenis pemasaran, yaitu offline marketing atau 
pemasaran tradisional yang dilakukan dengan mencari pelanggan atau klien melalui pertemuan secara langsung berhadapan dengan mereka yang mungkin tertarik menjadi pelanggan atau klien. Pemasaran yang lain menggunakan situs web sebagai media pemasaran yang dikenal sebagai online marketing. Dari sudut pandang bisnis, sosial media adalah tentang memungkinkan pembicaraan. Sosial media juga tentang cara pembicaraan ini bisa dihasilkan, dipromosikan, dan dijadikan pendapatan (Safko, 2016). Media sosial adalah tempat, alat bantu, layanan yang memungkinkan individu untuk mengekspresikan diri mereka untuk bertemu dan berbagi dengan rekan lainnya melalui teknologi internet. Sosial media adalah fase perubahan bagaimana orang menemukan, membaca, berbicara, dan membagi-bagikan informasi, berita, data kepada orang lain. Sosial media menjadi sangat populer karena kemudahan dan memberikan kesempatan kepada orang-orang untuk dapat terhubung secara online dalam bentuk hubungan personal, politik dan kegiatan bisnis. Sosial media menyediakan layanan komunikasi sosial.

Home industry adalah sebuah perusahaan yang anggota keluarganya secara langsung terlibat dalam kepemilikan dan jabatan atau fungsi. Bisnis keluarga mempunyai karakteristik dengan kepemilikannya atau keterlibatan lainnya dari dua peran atau lebih anggota keluarga yang sama dalam kehidupan dan fungsi bisnisnya. (Justin G. Longenecker, dkk:2013:35) Dalam hal ini dimaksudkan tentang usaha dan anggota keluarga yang berkecimpung di dalam usahanya.

Menurut Strauss dan Frost (2014), tujuh tahap dalam perancangan e-marketing adalah Situation Analysis (Analisis Situasi), E-Marketing Strategic Planning (Strategi Perencanaan E-Marketing), Objectives (Tujuan), E-Marketing Strategy (Strategi E- Marketing), Implementation Plan (Rencana Pelaksanaan), Budget (Anggaran), Evaluation Plan (Rencana Evaluasi). Adapun detail penjelasannya adalah :

1. Situation Analysis (Analisis Situasi) Tahap pertama merupakan awal dari konsep bisnis dengan melakukan analisis kekuatan, peluang, kelemahan serta ancaman bagi perusahaan. Dalam bagian ini, analisis situasi yang digunakan adalah analisis SWOT. Menurut Rangkuti (2014), analisis SWOT adalah indentifikasi berbagai faktor secara sistematis untuk merumuskan strategi perusahaan. Analisis ini disarankan pada logika yang dapat memaksimalkan Kekuatan (Strengths) dan Peluang (Opportunities), namun secara bersamaan dapat meminimalkan Kelemahan (Weaknesses) dan Ancaman (Threats). Proses pengambilan keputusan strategi selalu berkaitan dengan pengembangan misi, tujuan, strategi, dan kebijakan perusahaan. Dengan demikian perencanaan strategi (strategic planner) harus menganalisis faktor-faktor strategi perusahaan (kekuatan, kelemahan, peluang, dan ancaman) dalam kondisi yang ada saat ini. Hal ini disebut Analisis Situasi. Analisis SWOT membandingkan antara faktor internal Kekuatan (Strengths) dan Kelemahan (Weaknesses) dengan faktor eksternal Peluang (Opportunities) dan Ancaman (Threats) yang dihadapi dunia bisnis.

2. E-marketing Strategic Planning (Strategi Perencanaan E-marketing) Dalam tahap ini terdapat metodologi tujuh langkah sederhana yang membantu dalam mengevaluasi dan menganalisis peluang pasar (Market Opportunity Analysis/ MOA), yaitu: Mengidentifikasi kebutuhan pelanggan yang belum terpenuhi mengidentifikasi pelanggan tertentu yang akan dituju oleh perusahaan. Menilai keuntungan yang berkaitan dengan kompetisi menilai sumber daya perusahaan untuk memberikan penawaran menilai kesiapan pasar akan teknologi. Menentukan peluang secara konkret. Menilai peluang daya tarik bagi pelanggan. Strategi perencanaan e-marketing meliputi segmentation, targeting, differentiation, dan positioning

3. Objectives (Tujuan) Tujuan dalam e-marketing mencakup aspek tugas, kuantitas, dan waktu. Tugas (apa yang akan dicapai). Kuantitas yang terukur (seberapa banyak). Time frame (kapan). Sebagian besar e-marketing bertujuan untuk mencapai berbagai tujuan seperti berikut: Meningkatkan pangsa pasar. Meningkatkan jumlah komentar pada sebuah blog atau website. Meningkatkan pendapatan penjualan. Mengurangi biaya (misalnya biaya distribusi atau promosi). Mencapai tujuan merek (seperti meningkatkan kesadaran merek). Meningkatkan ukuran database. Mencapai tujuan Customer Relationship Management (CRM) (seperti meningkatkan kepuasan pelanggan, frekuensi pembelian, atau tingkat referensi pelanggan). Memperbaiki manajemen rantai suplai (seperti dengan meningkatkan koordinasi anggota, menambahkan mitra, atau mengoptimalkan tingkat persediaan).

4. E-marketing Strategy (Strategi E-marketing) Strategi e-marketing mencakup strategi mengenai 4P dan hubungan manajemen (relationship management) untuk mencapai tujuan rencana mengenai Product (Produk), Price (Harga), Place (Saluran Distribusi), dan Promotion (Promosi).

5. Implementation Plan (Rencana Pelaksanaan) Pada tahap ini perusahaan memutuskan bagaimana untuk mencapai tujuan melalui strategi yang efektif dan kreatif. Pemasar memilih bauran pemasaran (4P), strategi manajemen dan strategi 
lain untuk mencapai tujuan rencana dan kemudian menyusun rencana pelaksanaan (Implementation Plan). Perusahaan juga memeriksa untuk memastikan organisasi pemasaran yang tepat di tempat pelaksanaan (staf, struktur departemen, penyedia layanan aplikasi, dan lain-lain di luar perusahaan). Internet telah mengubah tempat pertukaran dari marketplace (seperti, interaksi face-to-face) menjadi marketspace (seperti, interaksi screen-to-face). Perbedaan utama adalah bahwa sifat hubungan pertukaran sekarang ditengahi oleh interface teknologi. Dengan perpindahan dari hubungan antar muka people-mediated menjadi technology-mediated, terdapat sejumlah pertim-bangan perancangan interface yang dihadapi. Menurut Rayport dan J.Jaworski. (2013), ada berbagai elemen dalam mendesain sebuah situs web, yaitu konteks (konteks dari situs mencerminkan nilai keindahan dan kegunaan dari situs tersebut), content (konten merupakan semua objek digital yang terdapat dalam sebuah web baik dalam bentuk audio, video, image ataupun text), community (komunitas merupakan ikatan hubungan yang terjadi antara sesama pengunjung atau pelanggan dari sebuah website karena adanya kesamaan minat atau hobi), customization (kostumisasi merupakan kemampuan situs untuk memodifikasi dirinya sesuai dengan keinginan penggunanya), communication (komunikasi antara perusahaan dengan pelanggan, terdiri dari Broadcast Dimension, Interactive Dimension, dan Hybrid Dimension), connection (kemampuan sebuah website untuk berpindah dari sebuah webpage ke webpage lainnya ataupun website lainnya dengan onclick baik pada text, images maupun toolbars yang lain), dan commerce (commerce merupakan fitur dari customer interface yang mendukung berbagai aspek dari transaksi perdagangan dan memiliki dimensi seperti (registration, shopping cart, security, credit card approval, one click shopping, order through affiliates, configuration technology, order tracking, delivery option).

6. Budget (Anggaran) Kunci dari perencanaan strategis adalah untuk mengidentifikasi hasil yang diharapkan dari suatu investasi. Selama pelaksanaan rencana, pemasar akan terus memantau pendapatan aktual dan biaya untuk melihat hasil yang telah dicapai. Internet merupakan salah satu tools yang dapat digunakan untuk memantau hasil karena catatan teknologi pengunjung setiap klik. Untuk mendapatkan informasi anggaran yang dapat dipertanggungjawabkan, perlu dibuat perhitungan tentang revenue forecast (perkiraan pendapatan), intangible benefits (manfaat tidak berwujud), cost savings (penghematan biaya), dan e-marketing costs (biaya emarketing).

7. Evaluation Plan (Rencana Evaluasi) Perencanaan e-marketing dilaksanakan, keberhasilannya tergantung pada evaluasi yang terus-menerus. Jenis evaluasi ini tergantung pada tujuan rencana. Untuk menentukan hasil pemasarannya, perusahaan dapat menggunakan balanced scorecard untuk mengukur kesuksesan dari program internet marketing dan apakah program internet marketing tersebut cocok sesuai dengan objektif dari perusahaan.

\section{METODOLOGI PENELITIAN}

Metodologi dari penelitian ini dibagi dalam desain penelitian dan subyek penelitian, metode pengumpulan data dan metode analisis data.

1. Desain Penelitian dan Subyek Penelitian Penelitian ini merupakan penelitian deskriptif observasional pada industri rumahan di desa Cipacing Bandung, menggunakan metode triangulasi, yang menggabungkan metode wawancara terstruktur, wawancara mendalam dan observasi terhadap sebagian warga cipacing dan media sosial yang digunakan. Subyek dalam penelitian ini adalah pengrajin yang dipilih secara purposive sampling. Subyek dipilih sesuai dengan kriteria: 1) merupakan pengrajin, 2) pernah menggunakan media sosial dalam komunikasi usahanya, 3) bersedia menjadi subyek penelitian. Total subyek yang direkrut dalam penelitian sebanyak 30 Orang.

2. Metode Pengumpulan Data Penelitian ini menggunakan data primer yang diperoleh berdasarkan wawancara terstruktur dan wawancara mendalam kepada pengrajin. Data yang diperoleh meliputi data karakteristik umum, data penggunaan sosial media dalam industri rumahan, termasuk tujuan, manfaat dan hambatan yang dihadapi

3. Analisis Data, Data yang diperoleh dianalisis menggunakan statistik deskriptif dan analisis kualitatif serta ditampilkan dalam bentuk table.

\section{HASIL DAN PEMBAHASAN}

Hasil dan pembahasan dari penelitian ini dibagi menjadi Karakteristik usaha industri rumahan yang menjadi subyek penelitian, penggunaan media sosial industri rumahan dan pengaruh penggunaana media sosial bagi industri rumahan.

1. Karakteristik Industri Rumahan Subyek dalam penelitian ini adalah merupakan pengrajin yang membuat kerajinan patung dari kayu dan bambu, 
dengan spesifikasi patung besar dan kecil serta lamanya menjalani usaha industri rumahan.

Tabel 1: Karakteristik Usaha Industri Rumahan

\begin{tabular}{llcc}
\hline NO & KARAKTERISTIK & JML & \% \\
\hline 1 & Jenis Patung & & \\
& Patung Dari Bahan Kayu & 20 & $66,67 \%$ \\
& Bekas & & \\
& Patung Dari Bahan Bambu & 10 & $33,33 \%$ \\
& Bekas & & \\
2 & Spesifikasi Patung & 15 & $50 \%$ \\
& Patung Besar & 15 & $50 \%$ \\
& Patung Kecil & & \\
& Lama Usaha & 25 & $83,33 \%$ \\
& 0-1 Tahun & 10 & $33,33 \%$ \\
& 1-4 Tahun & 5 & $16,66 \%$ \\
\hline & Di Atas 4 Tahun & & \\
\hline
\end{tabular}

2. Penggunaan Media Sosial pada UKM Sebagian warga cipacing dalam penelitian ini, menggunakan media sosial sebagai media informasi dan komunikasi kegiatan usahanya. Rata-rata yang digunakan adalah, facebook dalam menampilkan profil perusahan. E-mail, Black Berry Messanger (BBM) dan WhatsApp (WA) dan Instagram (IG) untuk gambar-gambar produksi.

Tabel 2: Media Sosial Yang Digunakan warga sebagian Cipacing

\begin{tabular}{lcc}
\hline \multicolumn{1}{c}{ VARIABEL } & $\begin{array}{c}\text { JUMLAH } \\
\text { N = 30 }\end{array}$ & $\%$ \\
\hline Blackberry Messanger & 25 & $83,33 \%$ \\
Facebook & 28 & $93,33 \%$ \\
Instagram & 20 & $66,67 \%$ \\
Whatsapp & 30 & $100 \%$ \\
\hline
\end{tabular}

3. Pengaruh Penggunaan Media sebagian warga Cipacing

Penggunaan media sosial bagi sebagian warga Cipacing sangat bermanfaat antara lain adalah, sebagai sarana kontak langsung dengan pemesan, sebagai sarana untuk mempromosikan hasil karya industry rumahan, mendata keinginan konsumen, menyampaikan respon ke konsumen dan sebagai dasar pengambilan keputusan dalam bertransaksi. Selain itu sosial media juga bermanfaat sebagai forum diskusi online, memantau perkembangan pelanggan, survei pelanggan, mendata kebutuhan penyalur/agen, menampilkan Foto produk.
Tabel 3: Manfaat Penggunaan Sosial Media sebagian warga Cipacing

\begin{tabular}{|c|c|c|c|}
\hline NO & MANFAAT & JML & $\%$ \\
\hline 1 & $\begin{array}{l}\text { Sarana Kontak Langsung } \\
\text { Dengan Pemesan }\end{array}$ & 30 & $100 \%$ \\
\hline 2 & $\begin{array}{l}\text { Sarana Untuk } \\
\text { Mempromosikan }\end{array}$ & 25 & $83,33 \%$ \\
\hline 3 & $\begin{array}{l}\text { Mendata Keinginan } \\
\text { Konsumen }\end{array}$ & 25 & $83,33 \%$ \\
\hline 4 & $\begin{array}{l}\text { Menyampaikan Respon Ke } \\
\text { Konsumen }\end{array}$ & 20 & $66,67 \%$ \\
\hline 5 & $\begin{array}{l}\text { Sebagai Pengambilan } \\
\text { Keputusan Transaksi }\end{array}$ & 30 & $100 \%$ \\
\hline 6 & Forum Diskusi & 30 & $100 \%$ \\
\hline 7 & $\begin{array}{l}\text { Memantau Perkembangan } \\
\text { Pelanggan }\end{array}$ & 20 & $83,33 \%$ \\
\hline 8 & Survei Pelanggan & 15 & $33,33 \%$ \\
\hline 9 & $\begin{array}{l}\text { Mendata Kebutuhan } \\
\text { Pelanggan }\end{array}$ & 20 & $66,67 \%$ \\
\hline 10 & $\begin{array}{l}\text { Mendata Kebutuhan } \\
\text { Penyalur }\end{array}$ & 15 & $33,33 \%$ \\
\hline 11 & $\begin{array}{l}\text { Menampilkan Foto Produksi } \\
\text { Hasil Industri }\end{array}$ & 30 & $100 \%$ \\
\hline
\end{tabular}

Sebagian warga Cipacing sangat merasakan begitu besar manfaat yang diperoleh dengan menggunakan sosial media sebagai sarana kegiatan pemasaran hasil industri rumahannya. Sosial media adalah salah satu unsur pendorong bagi sebagian warga cipacing untuk terus menggunakan dalam mengembangkan produk, melakukan komunikasi dengan konsumen dan pelanggan, penyalur, serta mengembangkan jaringan pasar yang lebih luas lagi, sehingga meningkatkan volume penjualan yang lebih besar. Hal ini seperti yang disampaikan oleh (Safko, 2016). Media sosial adalah tempat, alat bantu, layanan yang memungkinkan individu untuk mengekspresikan diri mereka untuk bertemu dan berbagi dengan rekan lainnya melalui teknologi internet. Sosial media adalah fase perubahan bagaimana orang menemukan, membaca, berbicara, dan membagibagikan informasi, berita, data kepada orang lain. Sosial media menjadi sangat populer karena kemudahan dan memberikan kesempatan kepada orang-orang untuk dapat terhubung secara online dalam bentuk hubungan personal, politik dan kegiatan bisnis. Sosial media menyediakan layanan komunikasi social. (Kartika, 2013)

Dari hasil penelitian ini menunjukkan bahwa sebagian warga Cipacing mendapatkan peningkatan pemesanan dari para konsumen setelah menggunakan sosial media. Disamping itu komunikasi juga efektif dan efisien karena bisa langsung berkomunikasi dan hemat. Kemudian mereka juga bisa mengembangkan bisnisnya lebih besar karena dapat bertransaksi langsung dan pembayaran juga bisa ditransfer, selain itu mampu mengembangkan bisnisnya dengan para agen/distributor. Berikut nya bahwa akibat sosial 
media mengakibatkan terjadinya peningkatan volume penjualan Karena penilaian volume penjualan berdasarkan hasil wawancara dengan para sebagian warga cipacing secara cross sectional, sehingga dalam mengukur peningkatan volume penjualan sebelum dan sesudah menggunakan sosial media berdasarkan perkiraan hasil akhir perbulan.

\section{KESIMPULAN DAN SARAN}

\section{Kesimpulan}

Kesimpulan yang bisa ditarik dari penelitian ini adalah, sebagian warga Cipacing menggunakan sosial media sebagai sarana untuk menjalani indutri rumahannya. Media sosial yang paling banyak digunakan adalah Facebook (FB), Whatsapp (WA), Instagram (IG), Blackberry Message (BBM). Manfaat yang paling dirasakan adalah komunikasi dengan para pelanggan dan pemasok lebih intenstif serta efektif dan efisien, karena dapat berkomunikasi langsung selama 24 jam/real time. Proses transaksi lebih mudah dan murah karena media komunikasi hanya mengeluarkan biaya pulsa untuk mendukung komunikasi. Media promosi yang paling baik karena bisa menampikan dan berbagi gambar lewat media ke komunitas dan masyarakat. Update informasi dapat dilakukan setiap waktu. Dan yang paling penting peningkatan volume penjualan rata-rata $100 \%$

\section{Saran}

Sebagian warga Cipacing disarankan lebih mengoptimalkan perkembangan teknologi informasi yang ada dengan maksimal. Artinya mulai melakukan inovasi-inovasi baru cara mempromosikan hasil industri rumahanya agar lebih menarik dengan memanfaatkan sosial media yang ada agar peningkatan volume penjualan secara continue bisa meningkat dan berkembang.

\section{DAFTAR PUSTAKA}

Chaffey, Dave, Richard Mayer, Kevin Johnston dan Fiona Ellis-Chadwick, 2015, Internet Marketing: Strategy, Implementattion And Practice, Pearson Education Limited, London, England.

Justin G. Longenecker, dkk., Kewirausahaan Manajemen Usaha Kecil, 2013, Salemba Empat, Jakarta.

Rayport, Jeffrey F. dan Bernard J.Jaworski, 2013, Introduction To E-Commerce, 2nd Edition, McGraw-Hill, New York.
Kotler, Philip dan Gary Amstrong, 2014, Principles of Marketing, 10th Edition, Pearson Education Inc. Upper Saddle River, New Jersey.

Kartika H, Bambang. 2013, WeChat, Social Messaging dengan Fitur Kaya Multimedia.

Katawetawaraks, C. \& Cheng, L. W. (2014). Online shopper behavior: Influences of online shopping decision. Asian Journal of Business Research.

McLeod, Raymond dan George Schell, 2010, Management Information Systems, 8th Edition, Prentice Hall, Newn Jersey. Rangkuti, F. (2014). Analisis SWOT teknik membedah kasus bisnis, Gramedia Pustaka Umum, Jakarta.

Jonathan Sarwono, K. Prihartono Perdagangan Online: Cara Bisnis di Internet, 2015, Elex media Komputindo, Jakarta.

Safko, Lon and David K.Brake 2016. The Social Media Bible: Tactics, Tools, and Strategies for Business Success, John Wiley \& Sons: New Jersey.

Strauss, Judy dan Raymond Frost, 2014, E-Marketing, 5th Edition, Prentice-Hall, Inc., Upper Saddle, New Jersey.

Turban, Efraim, R.Kelly Jr. Rainer dan Richard E.Potter, 2013, Introduction To Information Technology, 3rd Edition, John Wiley \& Sons, Inc., New York. 